\title{
Historical perspectives of The American Association for Thoracic Surgery: Claude S. Beck (1894-1971)
}

\author{
Tom P. Theruvath, MD, PhD, and John S. Ikonomidis, MD, PhD
}

Claude Schaeffer Beck (Figure 1), 25th president of The American Association for Thoracic Surgery (AATS), was born on November 8, 1894 as the youngest son to Martha Schaeffer and Simon Beck. He was born in Shamokin, a small town in eastern Pennsylvania. He completed his undergraduate studies in Lancaster, Pennsylvania at Franklin and Marshall College. At Franklin and Marshall, his mentor, Professor Richard Schiedt, was very influential on young Beck and introduced him to the experimental facets of science and the nature of laboratory research (Figure 2). Beck entered Johns Hopkins Medical School at the age of 23. Under the guidance of Dr Halsted, Beck developed an immense interest in surgery. In 1921, he graduated from Hopkins to pursue general surgical training at Yale University's New Haven Hospital. From 1923 to 1924, Beck served as the Arthur Tracy Cabot Fellow in Surgical Research at Harvard University under Dr Harvey Cushing, and it was there that he honed his research skills and his curiosity in continuous surgical investigations. He also served as an associate surgeon at the Peter Bent Brigham Hospital during this time, where he worked closely with Dr Elliott Cutler, who was a former resident of Dr Cushing.

When Dr Cutler accepted a new position at the Lakeside Hospital of Western Reserve University in 1924, Beck moved with him and served as Dr Cutler's first Crile Research Fellow in Surgery. Beck organized and set up the first surgical research laboratory at Western Reserve University. Following his time as a resident surgeon at Lakeside Hospital from 1926 to 1927 and an instructor in surgery at Western Reserve University from 1925 to 1928 , he rose through the academic ranks to assistant professor in 1928 and associate professor of surgery in 1933. In 1940, he received a tenured professorship in neurosurgery from Western Reserve University and held this title until 1952. In 1952, he received the title of professor of cardiovascular surgery, the first such title in the United States (Figure 3). In 1965, he was named professor emeritus.

\footnotetext{
From the Division of Cardiothoracic Surgery, Medical University of South Carolina, Charleston, SC.

Disclosures: Authors have nothing to disclose with regard to commercial support. Received for publication April 15, 2014; accepted for publication June 9, 2014; available ahead of print July 23, 2014

Address for reprints: John S. Ikonomidis, MD, PhD, Division of Cardiothoracic Surgery, Medical University of South Carolina, 25 Courtenay Dr, Suite 7030,

Charleston, SC 29425 (E-mail: ikonomij@musc.edu).

J Thorac Cardiovasc Surg 2015;149:655-60

$0022-5223 / \$ 36.00$

Copyright (c) 2015 by The American Association for Thoracic Surgery http://dx.doi.org/10.1016/j.jtcvs.2014.06.032
}

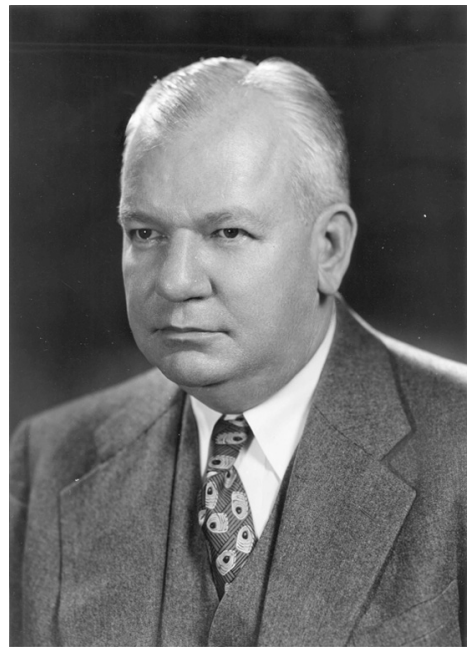

FIGURE 1. Professor Claude S. Beck. Courtesy of the Stanley A. Ferguson Archives at the University Hospitals Case Medical Center, Cleveland, Ohio.

\section{CURRICULUM VITAE HIGHLIGHTS}

In working with Dr Cutler, Beck first became interested in the investigation of coronary artery disease. Beginning in 1924, Cutler, with Beck's assistance, attempted to relieve mitral valve stenosis using a new instrument, the cardiovalvulotome, which was developed in his surgical research laboratory. ${ }^{1}$ Although operations for mitral valve stenosis, mostly due to rheumatic fever in that era, were being already performed in England, Cutler and Beck pioneered this work in the United States. ${ }^{2}$

Between 1925 and 1935, while investigating Pick's disease, ${ }^{3}$ Beck began to explore the concepts of the acute and chronically compressed heart with studies of the physiology and surgery for these conditions. Through these studies, acute and chronic compression of the heart were established as clinical entities, and the diagnostic triad of symptoms of hypotension, jugular venous distension, and muffled heart sounds were described and are recognized today as the famous Beck's triad. ${ }^{4}$

In addition to these studies, Beck investigated numerous other problems relating to surgery of the heart, and, in doing so, his laboratory made significant contributions to the advances in cardiac surgery (Figure 4). These included the study of penetrating and nonpenetrating cardiac trauma, the technique for suturing wounds of the heart, the use of anesthesia in surgical operations on the heart, and defibrillation of the ventricles. ${ }^{5-8}$ Beck also performed 


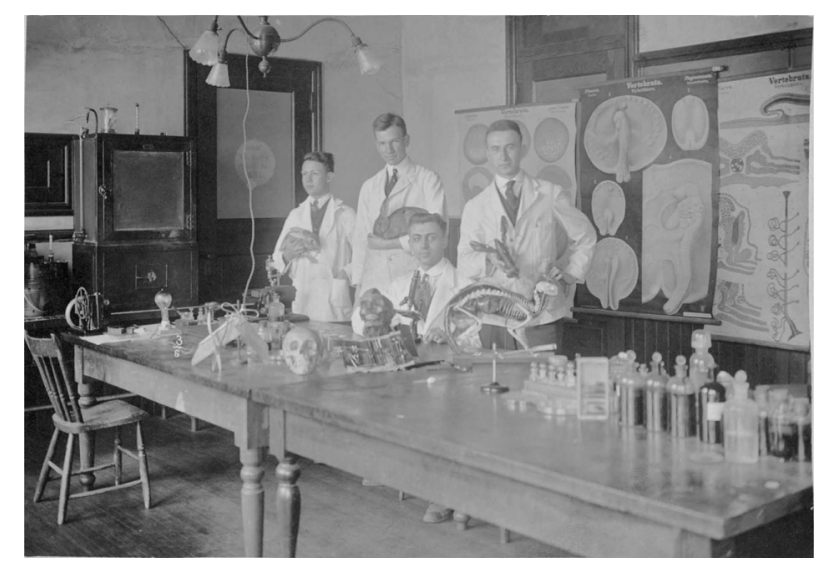

FIGURE 2. Young Dr Beck in the laboratory (second from the left). Courtesy of the Stanley A. Ferguson Archives at the University Hospitals Case Medical Center, Cleveland, Ohio.

many operations for pulmonary and mitral stenosis, coarctation of the aorta, and patent ductus arteriosus.

$\mathrm{He}$ had intensively investigated a method to deliver additional blood to the heart muscle in the presence of coronary artery occlusion. It was termed "cardiopericardiopexy" and was first performed on a human heart in 1935 after extensive canine laboratory experiments. The operation was designed to create a more homogeneous blood supply to the heart by development of a collateral circulation through intercoronary and extracoronary communications. This procedure, the "Beck I operation," consisted of the creation of granulomatous and vascular adhesions between the heart and pericardium by placement of either asbestos or talcum powder into the pericardial sac (Figure 5). In detail, Dr Beck described the procedure as follows ${ }^{9}$ :

The patient was placed on his right side with the left side up. If the blood pressure falls below $90 \mathrm{~mm} \mathrm{Hg}$, the operation is not started. Time is taken to observe the blood pressure. If the pressure remains below 90 for the next half-hour, the operation is not done and the patient is not acceptable for operation. By experience we learned to regard this as a rule not to be broken. The incision is placed between the fifth and sixth ribs extending from a point about $4 \mathrm{~cm}$ from the midline in front laterally for a distance of $20 \mathrm{~cm}$. Traction sutures are placed in the pericardium and held up by the weight of a hemostat. The lining of the parietal pericardium is abraded everywhere by special burs. Another incision is made parallel to the first incision but to the left of the nerve and a third incision splits the pericardium at right angles down to the coronary sinus.... The coronary sinus is observed. The ligature is tied around sinus plus a stilette $3 \mathrm{~mm}$ in diameter. The stilette is removed and partial

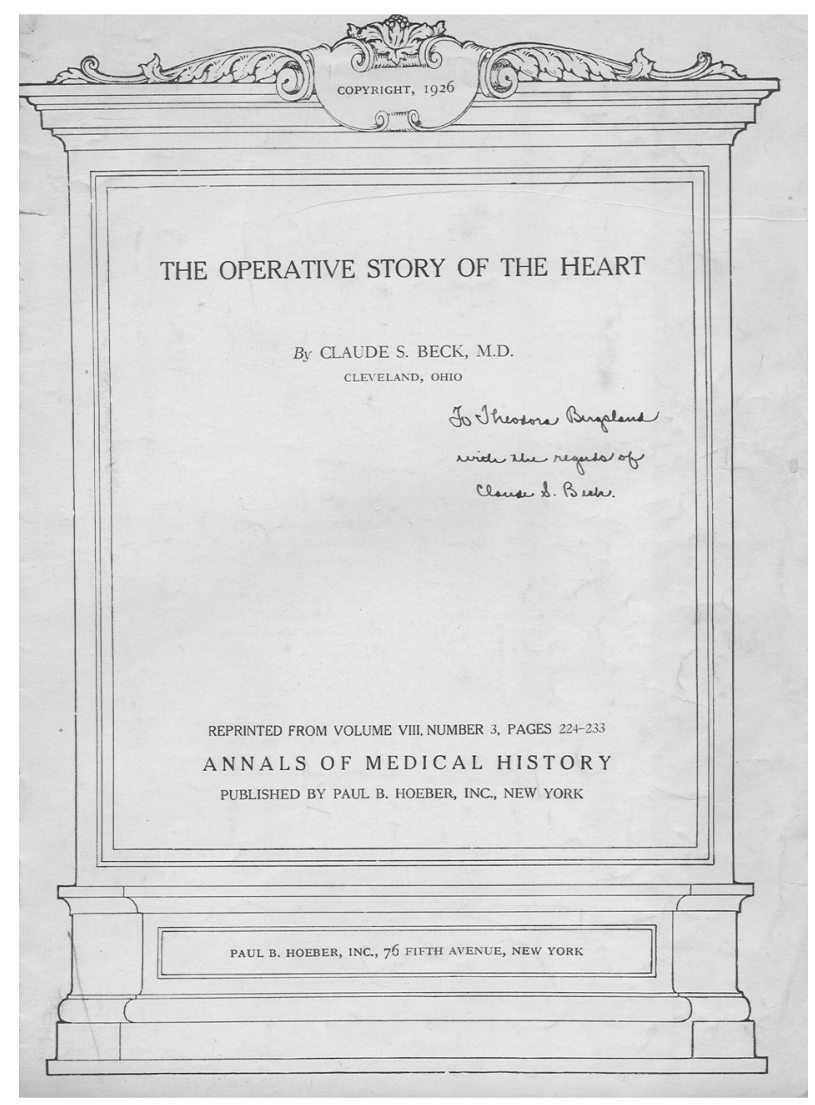

FIGURE 3. A signed copy of Dr Beck's article "The operative story of the heart" to Theodora Bergsland, a medical illustrator who worked with Dr Beck at the University Hospitals of Cleveland. Courtesy of the Stanley A. Ferguson Archives at the University Hospitals Case Medical Center, Cleveland, Ohio.

occlusion of the sinus is accomplished. This ligation is done after the surface of the heart is abraded, and also after $0.2 \mathrm{~g}$ of coarsely ground asbestos is applied to the surface of the heart. The mediastinal fat is then brought into contact with the heart over as wide an area as possible and the pericardium is loosely closed.

... The patient is given intranasal oxygen or is placed in an oxygen tent for 24 hours and ambulation is started. The patient is discharged in about two weeks.

In addition, vascular pedicles from adjacent structures were often used to furnish additional blood supply, in addition to the partial ligation of the coronary sinus in the hope that the resultant stasis would produce an increase in the formation of intercoronary collateral channels. ${ }^{10,11}$ Between 1935 and 1942, he performed 37 such operations on human hearts.

His work in the laboratory was interrupted in 1942, when Beck entered military service at the rank of colonel with the Medical Corps from 1942 to 1945 . He was also the surgical consultant to the Army Fifth Service Command. For his work at Fort Hayes in Columbus, Ohio, he was awarded 


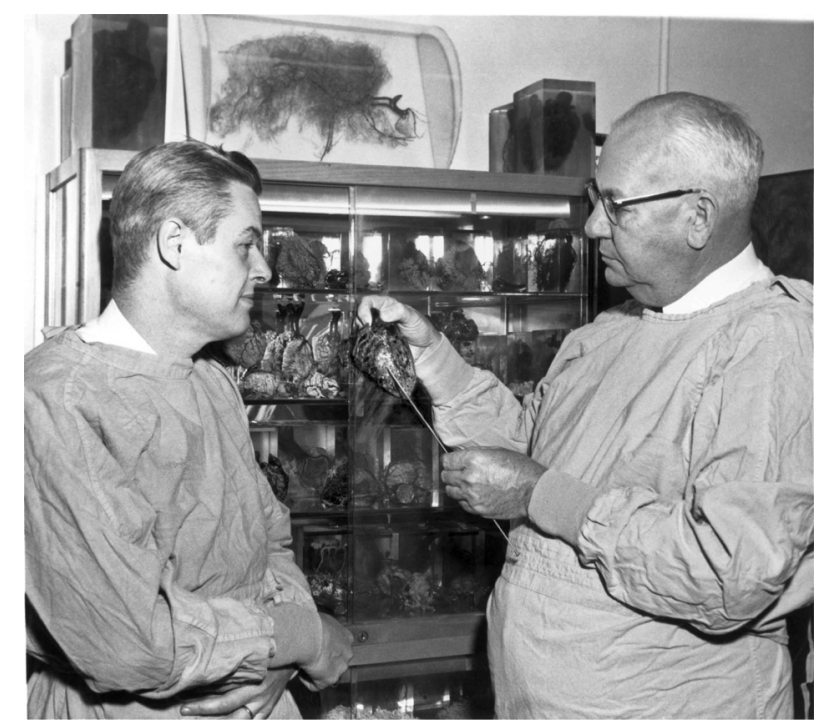

FIGURE 4. Professor Claude Beck in his laboratory with one of his research fellows, Dr David S. Leighninger. Courtesy of the Stanley A. Ferguson Archives at the University Hospitals Case Medical Center, Cleveland, Ohio.

the Legion of Merit in 1945 for outstanding service. On his return from the Army, Beck became even more convinced that many forms of heart disease could be treatable by surgical methods.

After his return from the Army, Beck developed his second iteration for mitigation of ischemia due to coronary arteriosclerosis, the "Beck II operation": it arterialized the venous system of the heart by constructing a vein graft between the aorta and coronary sinus, and it stimulated the growth of intercoronary communications (Figure 6). Dr Beck described his Beck II operation as follows':

Special clamps for the sinus and aorta are necessary. A fine continuous arterial suture is used. The opening in the aorta should not be more than 3 to $3.5 \mathrm{~mm}$ in diameter. A special instrument was designed to cut a circular piece out of the aorta. The graft is a piece of vein taken from the patient's elbow from either the basilic or cephalic vein. The graft should be about $1.5 \mathrm{~cm}$ in length and should not contain a valve. A piece of Mersilene suture material is placed around the coronary sinus close to its ostium in the right auricle. This ligature is placed at the first stage of the operation but it is not tied until the second stage, which is done two or three weeks after the first stage. This piece of Mersilene can be readily picked up at the second stage of the operation. It does not disintegrate or lose its tensile strength during the interval between operations. ... The second stage of the operation is done two to three weeks after the first stage. The same incision is opened. Usually there is some fluid in the chest cavity. This is removed. The lungs are retracted and the Mersilene thread is located. The sinus is then ligated on a $3 \mathrm{~mm}$ stilette as in the number one operation. Partial occlusion of the sinus reduces the size of the fistula. At the second stage of the operation the heart muscle appears pink and sometimes the veins are pink and not blue as they are in the first stage.

He performed 124 of these operations from 1948 to 1954. From 1954 on, given the technical difficulties of the Beck II operation, he returned to the simpler Beck I and treated more than 1000 patients with coronary heart disease. In developing the Beck I and Beck II operations, his laboratory made extraordinary contributions to the scientific community in the areas of heart surgery and the pathophysiology of angina pectoris. ${ }^{12-14}$

In 1947, 10 years after he had successfully defibrillated the heart of a dog, Beck successfully defibrillated a human heart, which had stopped beating during a heart operation using open chest cardiac stimulation. ${ }^{15}$ After this successful defibrillation, Beck began to formally train medical personnel in cardiac resuscitation in 1950, teaching both mouth-to-mouth ventilation of the lungs and open chest cardiac massage and defibrillation. ${ }^{16-18}$ In this way, he trained thousands of doctors and nurses in courses for cardiac resuscitation. Success with open chest defibrillation led Beck to advocate its use outside the hospital setting. However, with the development of the closed chest method in 1960, Beck helped to found "Resuscitation of America" in 1964, which promoted the teaching of closed chest resuscitation methods to responsibly lay rescue persons.

\section{ACCOMPLISHMENTS AND CONTRIBUTIONS TO THE FIELD OF CARDIOTHORACIC SURGERY}

For many years, Beck's laboratory was the only one in the United States devoted fully to the study of the heart. His contributions to our understanding of the heart through his individual efforts are outstanding. He has been no less than a pioneer in his study of acute and chronic compression of the heart, contusion of the heart, cardiac resuscitation, and alterations of the blood supply to the heart. He was the first to successfully remove tumors from the heart, ${ }^{19}$ to reverse a fatal heart attack, to defibrillate a human heart, ${ }^{15}$ and to perform operations for the surgical treatment of coronary artery disease. ${ }^{20}$ Although the medical community did not always understand or embrace Beck's advances in the new and complex field of cardiovascular surgery, Beck remained confidant in the future application of his studies and methods. The heart was to Beck, "the Great Northwest of Surgery" and he considered himself its devoted explorer. ${ }^{21}$

\section{SUMMARY OF AATS PRESIDENTIAL ADDRESS}

Dr Claude Beck's presidential address, "The Direct Approach to Cardiovascular Diseases," presented at the 

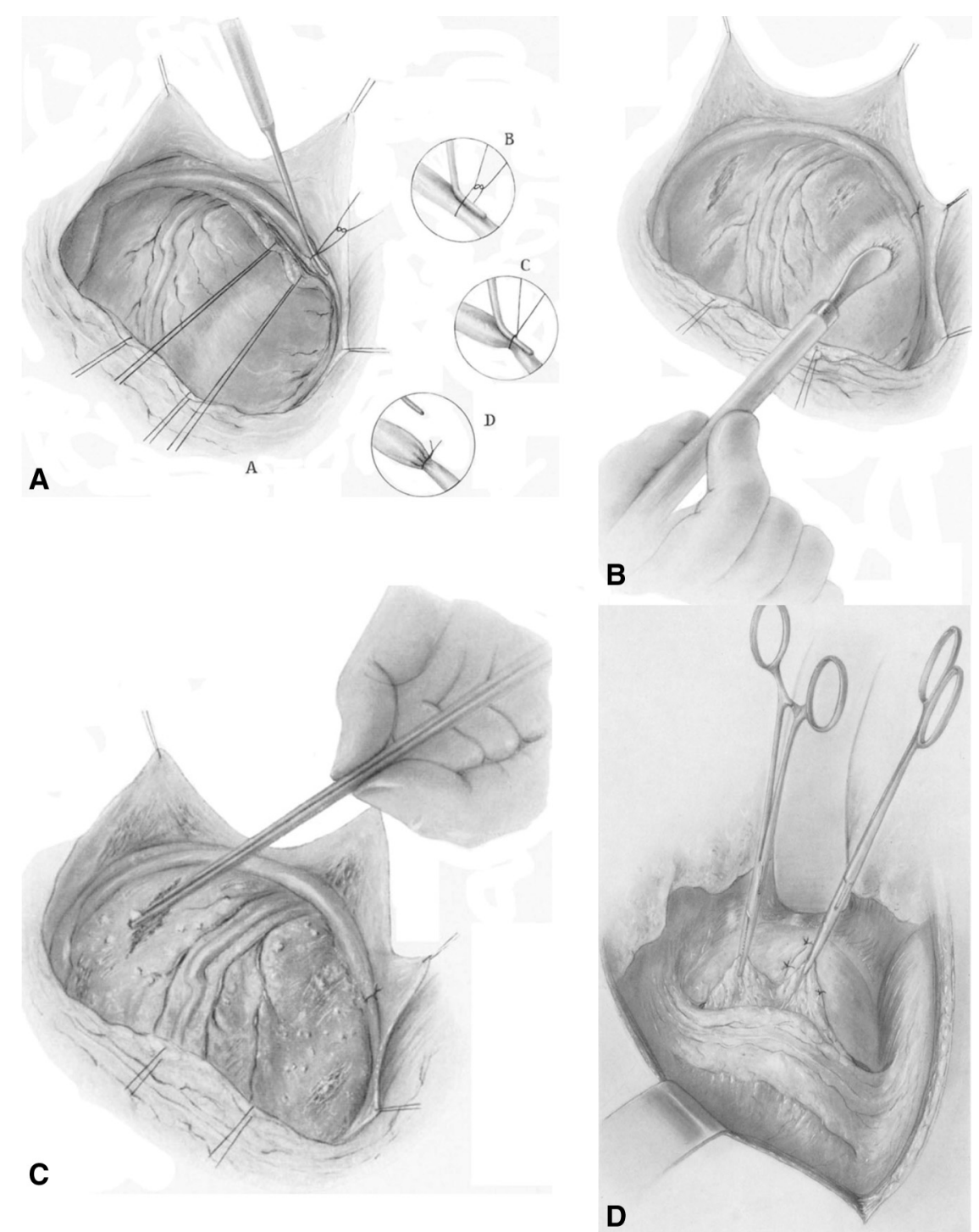

FIGURE 5. Illustration of the Beck I operation from his chapter in the Encyclopedia of Thoracic Surgery, Volume II, Special Part 1. ${ }^{9}$ A, Creation of partial coronary sinus occlusion. B, Abrasion of the parietal pericardium overlying the ventricles. C, Coarsely ground asbestos (0.2-0.4 g) sprinkled over the entire surface of the heart. D, Completion by placement of mediastinal fat over the heart and loose closure of the pericardium. Reprinted with permission. ${ }^{9}$

26th Annual Meeting of the AATS in Detroit, Michigan, May 29 to 31, 1946, was influenced by his extremely successful physician/scientist career in an era in which significant notions and contributions to cardiothoracic surgery gave birth to this field. ${ }^{14}$ However, the field remained restrained for another 7 years until the use of the cardiopulmonary bypass machine. It would become a necessary part of the direct approach into the heart, revolutionizing the entire field of cardiovascular medicine, as predicted by Dr Beck during his AATS presidential address, long before its regular use.

Dr Beck started his presidential address by clarifying the significance of coronary artery disease, being as important as cancer and contributing to almost the same mortality as cancer. He emphasized the need to establish a public appeal for the study of cardiovascular disease and thereby increase the funding for intensifying research in this field. Dr Beck also emphasized that, comparable to a car breakdown, which needs the hood lifted and the engine compartment looked at, a direct approach should be applied to understanding and treatment of cardiovascular diseases. This he emphasized in stark contrast to the prevailing diagnostic approaches using stethoscopes, electrocardiography, radiographs, and physiologic measurements of the arterial and venous pressures. He then gave multiple examples of direct approaches to the heart and vasculature, not only to diagnose, but also to treat the underlying defects. One of these is traumatic injury to the heart and great vessels and their respective direct repair with sutures. He also described decompression in the setting of cardiac tamponade, with its 

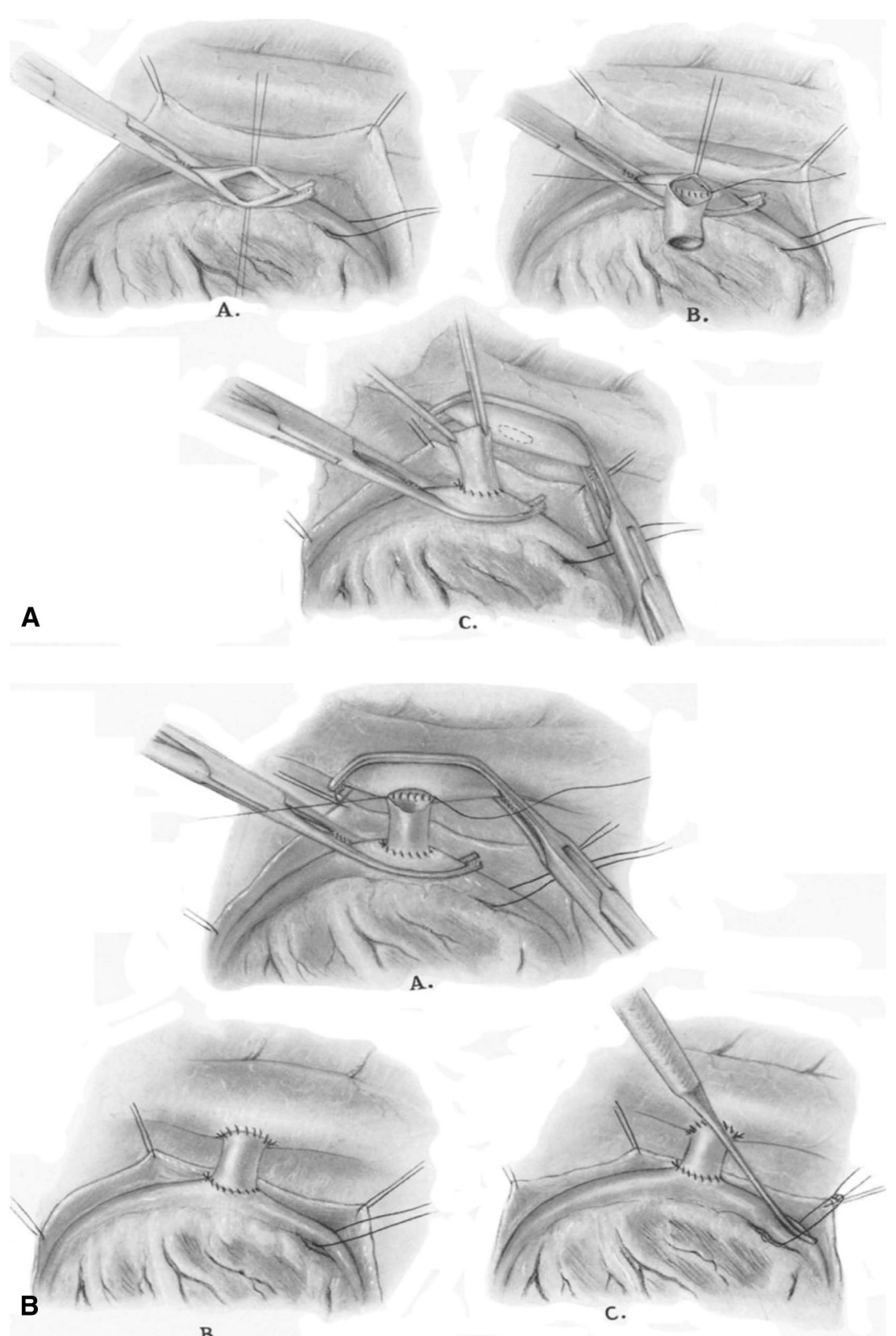

FIGURE 6. Illustration of the Beck II operation from his chapter in Encyclopedia of Thoracic Surgery, Volume II, Special Part 1..$^{9}$ A, Creation of the anastomosis between the coronary sinus, using a vein graft, and the descending aorta. B, Completed shunt with partial occlusion of the sinus, which was done at the second stage of the operation. Reprinted with permission. ${ }^{9}$

diagnostic triad bearing his name. Dr Beck pointed to the importance of deliberate identification and solution finding of cardiovascular problems in the research laboratory, followed by direct application at the bedside. Although the role of operative interventions for coronary artery disease was not a cure, he noticed that the definite benefit for a condition that was once considered hopeless warranted extension to other problems in cardiovascular disease. He specifically referred to the work on tetralogy of Fallot as one of the most important contributions made to surgery in his lifetime.

Dr Beck also pointed to the advancements in resuscitation, including defibrillation and the need for certification by the American Board of Surgery, to standardize the knowledge on resuscitation, a field in which he has made significant contributions himself. The topic of coronary artery disease, also mainly investigated and advanced by the laboratories of Dr Beck, was presented 
in more detail in his address, with the notion of intercoronary and extracoronary communications to improve blood flow to myocardial tissue. Finally, as the principal investigator in one of the most prolific surgical research laboratories in the United States, he underlined the need to preserve a conservative and critical attitude toward new clinical applications. In finishing his address, he gave examples of possible developments in the future, including vascular transplantation and exclusion of the heart from the circulation to pursue, not only safe approaches to the heart and its surfaces, but also to gain access to the interior compartments to address problems so commonplace and standard today.

\section{PERSONAL LIFE}

Dr Claude S. Beck met his wife Ellen Manning in Boston, Massachusetts, during his fellowship at Harvard Medical School, and they married in 1928. They had 3 daughters, Mary Ellen, born in 1932, Kathryn born in 1934, and Martha Ann, born in 1938. Dr Beck's wife Ellen passed away in 1986, having outlived him by 15 years after his death in 1971 of a stroke at age 77.

Figures 1 to 4 have been provided by the Stanley A. Ferguson Archives at the University Hospitals Case Medical Center in Cleveland, Ohio and permission to publish was granted. The authors would like to thank Dianne O'Malia, University Archivist, Stanley E. Ferguson Archives, University Hospitals Case Medical Center, Cleveland, Ohio, for her assistance in providing these images. Figures 5 and 6 have been reproduced from E. Derra (editor), Encyclopedia of Thoracic Surgery (Handbuch Der Thoraxchirurgie), Duesseldorf: Springer-Verlag; 1959, with kind permission from Springer Science and Business Media.

\section{References}

1. Beck CS, Cutler EC. A cardiovalvulotome. J Exp Med. 1924;40:375-9.

2. Holman E, Beck CS. The physiological response of the circulatory system to experimental alterations: III. The effect of aortic and pulmonic stenoses. $J$ Clin Invest. 1926;3:283-98.

3. Beck CS, Griswold RA. Pericardiectomy in the treatment of the Pick syndrome; experimental and clinical observations. Arch Surg. 1930;21:1064-111.

4. Beck CS. Two cardiac compression triads. JAMA. 1935;104:714-6.

5. Beck CS. Further observations on stab wounds of the heart. Ann Surg. 1942;115: 698-704.

6. Beck CS. The direct approach to the heart. Surg Clin North Am. 1969;49: 643-8.

7. Beck CS. The management of wounds of the heart. Surg Clin North Am. 1958;38: 1557-68.

8. Beck CS, Rand HJ III. Cardiac arrest during anesthesia and surgery. JAMA. 1949; 141:1230-3.

9. Beck CS. Surgical operations for coronary artery disease. special part 1. In: Derra E, ed. Encyclopedia of Thoracic Surgery, vol II. Duesseldorf: SpringerVerlag; 1959:779-833.

10. Beck CS, Tichy VL. The production of a collateral circulation to the heart. Am Heart J. 1935;10:874.

11. Gage AA, Olson KC, Chardack WM. Cardiopericardiopexy: an experimental evaluation. Ann Surg. 1958;147:289-94.

12. Beck CS. The development of a new blood supply to the heart by operation. Ann Surg. 1935;102:801-13.

13. Beck CS. Principles underlying the operative approach to the treatment of myocardial ischemia. Ann Surg. 1943;118:788-806.

14. Beck CS. The direct approach to cardiovascular diseases. J Thorac Surg. 1946; 15:297-301.

15. Beck CS, Weckesser EC, Barry FM. Fatal heart attack and successful defibrillation: new concepts in coronary artery disease. JAMA. 1956;161: 434-6.

16. Beck CS. Acute cardiorespiratory failure; requirements for successful resuscitation. Ohio Med. 1949;45:1076.

17. Beck CS, Leighninger DS. Resuscitation for cardiac arrest. Postgrad Med. 1959; 25:516-27.

18. Beck CS, Leighninger DS. Resuscitation of the heart. Minn Med. 1959;42: 1035-43.

19. Beck CS. An intrapericardial teratoma and a tumor of the heart: both removed operatively. Ann Surg. 1942;116:161-74.

20. Beck CS, Hahn RS, Leighninger DS, McAllister FF. Operation for coronary artery disease. JAMA. 1951;147:1726-31.

21. Beck CS. The last great northwest of surgery. Ohio State Med J. 1968;64: $335-40$. 